\title{
DIREITO DE IGUALDADE NO ACESSO E NA MANUTENÇÃO NO SISTEMA BANCÁRIO
}

\author{
RIGHT OF EQUALITY IN ACCESS AND MAINTENANCE \\ IN THE BANKING SYSTEM
}

\author{
Maria Emília Teixeira ${ }^{1}$ \\ Universidade Portucalense, Porto, Portugal
}

\begin{abstract}
Resumo: O Banco de Portugal reconheceu recentemente que possuir uma conta de depósito à ordem é conditio sine qua non para que qualquer cidadão tenha acesso ao sistema bancário. De facto, possuir uma conta de depósito é, atualmente, essencial pois não a ter significa não aceder a certos bens ou serviços, podendo consubstanciar um fator de estigmatização ou exclusão social, como é admitido no preâmbulo do Decreto-Lei n. ${ }^{\circ}$ 27-C/2000 de 10 de Março, que consagra o regime jurídico do sistema de acesso aos serviços mínimos bancários. Constata-se, portanto, que o uso de certos meios de pagamento automático e do cartão de débito se tornou um hábito social e económico natural e generalizado. Comprova-se essa circunstância, por exemplo, quando se exige que certo beneficiário possua uma conta de depósito à ordem para que possa receber determinadas pensões ou subsídios sociais. Contudo, estas contas bancárias não são gratuitas e as condições para que se possa aceder às mesmas nem sempre viabilizam, de forma igualitária, a que todo e qualquer cidadão as possa ter. Não se concebe que reformados ou desempregados sejam obrigados a possuir certos saldos médios anuais ou a possuírem um vencimento mensal domiciliado para que fiquem isentos de comissões e cobranças de despesas de manutenção de conta. Urge, por conseguinte, analisar se o atual sistema de acesso aos serviços bancários é apto na eliminação deste fator de exclusão ou se, por outro lado, não se deveria ser mais ousado e avançar para um regime de contas de depósito à ordem totalmente gratuitas e não apenas tendencialmente gratuitas como naquele regime acontece.
\end{abstract}

Palavras-Chave: Sistema bancário, Acesso igualitário, Depósito à ordem.

\begin{abstract}
The "Banco de Portugal" recently recognized that owning a demand deposit account is a conditio sine qua non for any citizen to have access to the banking system. In fact, to possess a demand deposit account is currently essential, not having one means not to be able to access certain goods or services, and may constitute an stigmatizing factor or a social exclusion factor, as said in the preamble of DL n. ${ }^{\circ}$ 27- C / 2000 of 10 March, that creates the legal system of banking minimum services access. It appears, therefore, that the use of certain automatic payment methods and the use of debit cards has became a widespread social habit in our economic society. We can verify this fact when it requires that one beneficiary has a demand deposit account in order for him to receive certain social benefits. However, these bank accounts aren't free and the terms to access the accounts aren't the same for every citizen. It's not conceivably that unemployed and retired citizens may be forced to own certain annual average balances or to have monthly income consignated to a bank account, in order for them to be free of any account maintenance expenses. It is urgent, therefore, to examine whether the current use of bank minimum services access is able to remove this exclusion factor or if, on the other hand,
\end{abstract}

\footnotetext{
${ }^{1}$ Maria Emília Teixeira, Doutora em Direito Civil/ Comercial, investigadora do Instituto Jurídico Portucalense na linha de investigação "Capital, Labour, Tax and Trade" e professora auxiliar do Departamento de Direito da Universidade Portucalense Infante D. Henrique. Universidade Portucalense, Instituto Jurídico Portucalense - IJP, Rua Dr. António Bernardino Almeida, 541-619, CP 4200-486, Porto, Portugal. Gabinete 410. E-mail institucional: emiliat@upt.pt.
} 
we should be more bold and create a legal system of totally free demand deposit account and not a partial free system as the one that we have nowadays.

Keywords: Banking system, Equal access, Demand deposit.

\section{Introdução}

A verdade é que todos nós estamos mais predispostos ou aptos a divulgar e a publicitar informações ou factos que nos tragam, de algum modo, certos benefícios, sejam de ordem económica ou pessoal. Contudo, se dessa divulgação puder resultar algum prejuízo para a nossa atividade ou bem-estar, ela não será efetuada de forma tão eficaz, não atingindo a extensão de destinatários que, sem grande empenho ou esforço de maior, certamente conseguiríamos.

O mesmo princípio aplica-se às instituições bancárias e tal sucede por duas razões: a politicamente correta e a real.

A primeira fundamenta-se na necessidade de prossecução do interesse público no bom funcionamento da economia, evitando-se qualquer ato suscetível de afetar a confiança depositada pela sociedade nestas instituições, a qual é vital para a estabilidade do sector bancário e, inerentemente, do sistema financeiro em geral. Na realidade, se considerarmos o atual modelo de Banca Universal, é sabido que a instabilidade desta necessariamente se repercutirá noutros sectores, cujo equilíbrio e solidez são igualmente condições fundamentais para o bom funcionamento do sistema financeiro em geral.

Mas a razão real pela qual as instituições bancárias optam por proceder a uma divulgação discreta de certos serviços pode provir da sua conveniência na não adesão em massa a esses serviços, pois poderia ocasionar um impacto negativo nos lucros da sua atividade. A verdade é que, quando assim é, a instituição bancária, obrigada a proceder a essa divulgação ${ }^{2}$, fá-lo de forma comedida e circunspecta. Divulga, mas não publicita. Sem grande exuberância ou prolixidade.

É o que sucede com as contas de serviços mínimos bancários.

\section{Dos Serviços Mínimos Bancários}

\subsection{Da obrigação de divulgação pelas instituições bancárias}

Não obstante o modelo oficial de divulgação de serviços mínimos bancários,

\footnotetext{
${ }^{2}$ Art. $7 .^{\circ}-$ A, n. ${ }^{\circ}$ 2, do Decreto-Lei n. ${ }^{\circ}$ 27-C/2000 de 10 de Março.
} 
previstos no Aviso do Banco de Portugal n. ${ }^{\circ}$ 2/2015 ${ }^{3}$, onde se impõe que as instituições de crédito divulguem de forma pública e permanente nos seus balcões e sites toda a informação sobre os serviços mínimos bancários, e que afixem em lugar visível em todos os seus balcões e locais de atendimento ao público, um cartaz em formato A4 onde se prestem todas as informações e condições relativas aos serviços mínimos bancários, quantos de nós já tomou conhecimento destes serviços através das instituições bancárias? Os ditos cartazes estão afixados. Mas o que o aviso de Banco de Portugal não determina é o local onde devem os mesmos ser afixados, pelo que poderá ser em qualquer zona da agência bancária ou do local de atendimento e existem tantas, umas mais visíveis que outras.

\subsection{Do regime jurídico}

Mas em que consistem afinal os Serviços Mínimos Bancários?

O seu regime legal aparece-nos consagrado no Decreto-Lei n. ${ }^{0}$ 27-C/2000 de 10 de Março, tendo sido já alterado pela Lei n. ${ }^{\circ}$ 19/2011, de 20 de Maio, pelo DecretoLei n. ${ }^{\circ}$ 225/2012, de 17 de Outubro e, mais recentemente pela Lei n. ${ }^{\circ}$ 66/2015, de 6 de Julho, cuja entrada em vigor ocorreu em 4 de Outubro de 2015. Na realidade, foi este último diploma que veio consagrar a obrigatoriedade de as instituições de crédito que prestem ao público os serviços incluídos nos serviços mínimos bancários - sejam bancos, caixas económicas, caixa central e caixas de crédito agrícola mútuo disponibilizarem os serviços mínimos bancários. Até à Lei n. ${ }^{\circ}$ 66/2015, a prestação destes serviços era voluntária e dependia se a instituição queria aderir a estes serviços ou não, embora a maior parte dos bancos portugueses tivessem aderido voluntariamente. Já dizia o preâmbulo do diploma legal que criou os serviços mínimos bancários que a atividade financeira e bancária assume uma relevância dominante na organização económica e social das famílias e que a "indisponibilidade de certos serviços financeiros e bancários, além de óbice ao rápido acesso ou mesmo entrave à obtenção de bens e serviços, muitas vezes de carácter essencial, é suscetível de consubstanciar fator de exclusão ou estigmatização social”. Dessa forma, para evitar a dificuldade no acesso a certos serviços por parte de certos particulares o Estado criou os serviços mínimos bancários.

\footnotetext{
${ }^{3}$ Alterou o Aviso do Banco de Portugal n. ${ }^{\circ}$ 15/2012 e deve ser complementado com a Instrução n. ${ }^{\circ}$ $15 / 2015$
} 
Os serviços mínimos incluem a abertura e a manutenção da sua conta de depósito à ordem, um cartão de débito para movimentação da conta, acesso à movimentação da conta de serviços mínimos bancários através de caixas automáticos, serviço de homebanking e balcões da instituição de crédito, realização de depósitos, levantamentos, pagamentos de bens e serviços, débitos diretos e transferências intrabancárias nacionais, sem restrição quanto ao número de operações que podem ser realizadas ${ }^{4}$. Mediante a reunião de certos requisitos, qualquer pessoa poderá proceder à abertura de uma conta de serviços mínimos bancários, que consiste numa conta de depósito à ordem, ou então solicitar a conversão da sua atual conta de depósito à ordem numa conta de serviços mínimos bancários, sem que por essa conversão o banco possa cobrar qualquer comissão, custo ou encargo ${ }^{5}$.

Os requisitos para se obter uma conta de serviços mínimos são cumulativos e requer que o candidato não seja titular de nenhuma outra conta de depósito à ordem, seja no banco onde requer a abertura ou a conversão de conta ou em qualquer outro banco e autorizar o banco a proceder à confirmação da veracidade desta informação após consulta junto das entidades gestoras dos sistemas de funcionamento dos cartões de crédito e débito.

É totalmente vedada a possibilidade de as instituições de crédito condicionar a conversão ou a abertura de uma conta de serviços mínimos à assinatura de documentos, impressos ou comprovativos adicionais àqueles que são necessários para a abertura de uma conta de depósito à ordem, ou à aquisição de produtos ou serviços adicionais. A conta de serviços mínimos bancários pode ser titulada por uma ou por várias pessoas singulares, desde que todos os titulares reúnam os requisitos de abertura supra descritos, exceção feita se um dos contitulares da conta de serviços mínimos bancários for uma pessoa singular com mais de 65 anos ou dependente de terceiros, considerando-se dependente de terceiros aquele que apresente um grau de invalidez permanente, devidamente comprovado pela entidade competente, igual ou superior a $60 \%{ }^{6}$.

\subsection{Vantagens do sistema de serviços mínimos bancários}

A principal vantagem da conta de serviços mínimos bancários está no limite máximo possível que pode ser cobrado pelas instituições de crédito pela prestação de

\footnotetext{
${ }^{4}$ Cfr. Art. $2 .^{\circ}$, n. ${ }^{\circ}$ 2, al. a) do Decreto-Lei n. ${ }^{\circ}$ 27-C/2000 de 10 de Março.

${ }^{5} \mathrm{Cfr}$. Art. $4 .^{\circ}$, n. $^{\circ} 2$ do Decreto-Lei n. ${ }^{\circ} 27-\mathrm{C} / 2000$ de 10 de Março.

${ }^{6}$ Cfr. Art. $4 .^{\circ}-\mathrm{B}$, n. ${ }^{\circ} 1$, 3 e 4 do Decreto-Lei n. ${ }^{\circ}$ 27-C/2000 de 10 de Março.
} 
tais serviços. Assim, não podem ser cobradas "comissões, despesas ou outros encargos que, anualmente, e no seu conjunto, representem valor superior ao equivalente a $1 \%$ da remuneração mínima mensal garantida”, ou seja, não poderá ser cobrada qualquer despesa acima de 5,30 euros por ano. Além disso, é ainda fornecido um cartão de débito a cada titular o cujo custo e anuidade já está incluída naquele montante, sendo cobrada a emissão de cartão de débito apenas se o titular da conta solicite a substituição do cartão de débito antes de decorridos 18 meses sobre a data da respetiva emissão, exceto se a validade for inferior a este prazo ou, então, a causa de substituição seja imputável à instituição de crédito, conforme dispõe o art. 3. ${ }^{\circ}$, n. ${ }^{\circ} 1$ e 2 do Decreto-Lei n. ${ }^{\circ}$ 27-C/2000 de 10 de Março. As instituições de crédito só poderão resolver o contrato de abertura de conta de serviços mínimos se se constatar que o titular da conta de serviços mínimos bancários deixou de reunir os requisitos de acesso aos serviços mínimos bancários ou se, um ano após a abertura ou conversão de conta de depósito à ordem em conta de serviços mínimos bancários, a mesma apresentar um saldo médio inferior a 5\% da remuneração mínima mensal garantida, ou seja, inferior a 26,50 euros e não tiver sido realizada, nos seis meses, qualquer operação bancária.

De referir ainda que, segundo dados revelados pelo Banco de Portugal, em 31 de dezembro de 2015 existiam 24.068 contas de serviços mínimos o que, comparativamente com o final do ano de 2014, representa um aumento de $73 \%$.

\section{Paralelismo com as “constas-base”}

Atualmente, encontra-se na discussão na especialidade ${ }^{7}$ uma proposta de lei da autoria do $\mathrm{PCP}^{8}$, tendo sido discutida na generalidade e aprovada a 8 de Janeiro deste ano $^{9}$, que visa a criação e disponibilização de “contas-base” aos clientes bancárias onde nenhuma despesa, comissão ou custo pode ser cobrado, sendo totalmente gratuitas.

Cremos que estas contas, face ao regime legal atual vigente sobre os serviços mínimos bancários e acima explicitado, não acrescentam nenhuma novidade significativa, considerando que o desígnio prosseguido por ambos os tipos de conta é o mesmo. A única diferença substancial residirá na gratuitidade das “contas-base” face às contas de serviços mínimos que, como se viu, são tendencialmente gratuitas. Se o

\footnotetext{
${ }^{7}$ Na comissão competente que é a Comissão de Orçamento, Finanças e Modernização Administrativa.

${ }^{8}$ Cfr. Projeto de Lei 92/XIII,

${ }^{9}$ Votação na Reunião Plenária n. ${ }^{\circ}$ 23, com os votos a favor do PCP, BE, PAN, PEV e PS, e votos contra do PSD e CDS-PP.
} 
impacto de acesso em massa às contas de serviços mínimos traz preocupações à atividade das instituições de crédito, a adesão às “contas-base” pode configurar um pesadelo.

\section{Conclusões}

Isto posto, crê-se que as contas de serviços mínimos divulgadas de forma conveniente servem o propósito que as “contas-base” visam, pelo que estas poderão apenas configurar um ideal populista que nada acrescenta de relevante e poderá apenas servir de "isco para pesca mais distraída ou menos avisada”, além de que, devido ao impacto negativo que pode acarretar para o sistema financeiro em geral a implementação de certas medidas, como esta que ora se propõe, julgamos que além da insistência na divulgação eficaz das contas de serviços mínimos, se deveria fazer, e à medida que a adesão às mesmas fosse evoluindo, um estudo de impacto destas na atividade das instituições que as fornecem.

\section{Referências Bibliográficas}

Aviso do Banco de Portugal n. ${ }^{o}$ 2/2015.

Decreto-Lei n. ${ }^{\circ}$ 27-C/2000 de 10 de Março.

Instrução n. ${ }^{\circ}$ 15/2015.

Projeto de Lei 92/XIII do Partido Comunista Português [em linha]. <http://app.parlamento.pt/webutils/docs/doc.pdf?path=6148523063446f764c32 46795a5868774d546f334e7a67774c336470626d6c7561574e7059585270646d 467a4c31684a53556b76644756346447397a4c33427162446b794c56684a5355 6b755a47396a\&fich=pj192-XIII.doc\&Inline=true > [28 agosto 2016]. 